\title{
ISOLATION AND IDENTIFICATION OF MYCOPLASMA FROM CASES OF PNEUMONIA IN FEEDLOT LAMBS
}

M.A. HAMAD and Z.M. AL-JUMAA

Department of Microbiology, College of Veterinary Medicine, University of Musol, Mosul, Iraq

E-Mail: sandyz85@ymail.com

\section{ABSTRACT}

Received at: 8/5/2014

Accepted: 21/5/2014
The present study was performed to detect and isolate the Mycoplasma as causative agent of atypical pneumonia in feedlot lambs. Samples (180) were collected from lambs suffering clinically from pneumonia. During the period October 2013 to March 2014. These samples were included nasal swabs (60), tracheal swabs (60) and infected lungs (60). Samples were cultured in the selective media (Mycoplasma Broth Base) and incubated aerobically at $35 \mathrm{C}^{\circ}$ for $4-14$ days. When turbidity appeared inoculum of each broth was cultured on Mycoplasma Glucose Agar medium and incubated at $35 \mathrm{C}^{\circ}$ for $7-14$ days in candle jar. Primary isolation was demonstrated by color changing of diphasic media, The ability of staining with Dennis stain, reduction of Tetrazolium, red blood cell lysis and fried egg appearance of Mycoplasma colonies was also studied. The results of present study also showed the total rate of Mycoplasma isolation (49.4\%) from total samples, and the highest rate of isolation was from Nasal swabs (58\%). While, the rate of isolation from Tracheal swabs $(55.3 \%)$ and from infected lungs $(35 \%)$.

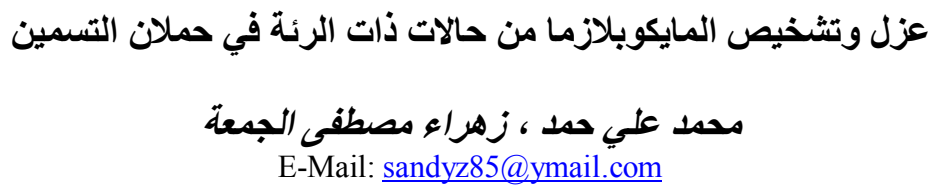

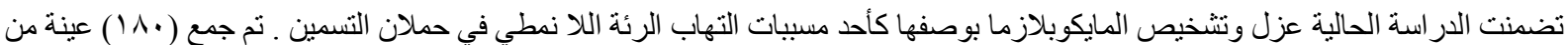

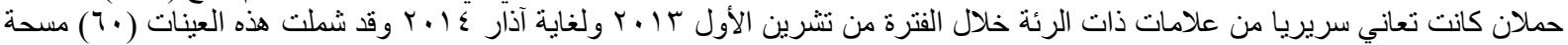

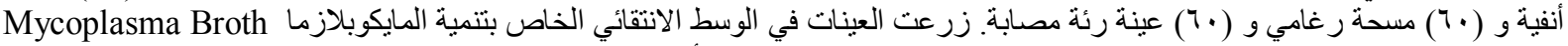

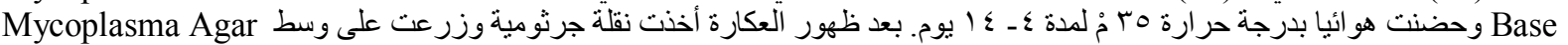
Base medium

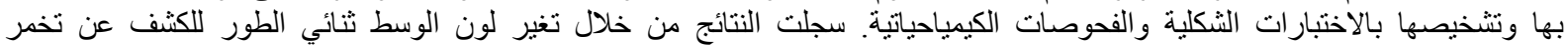

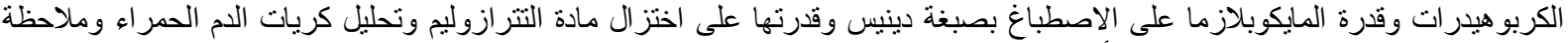

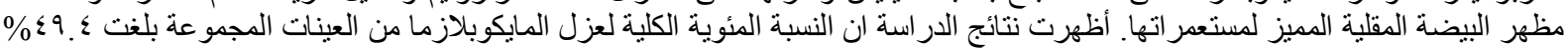

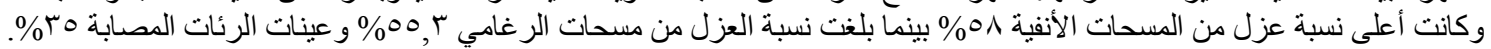

\section{INTRODUCTION المقدمـة}

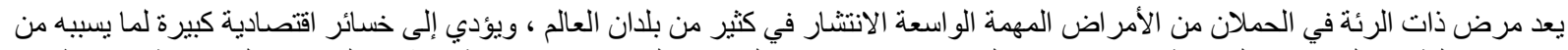

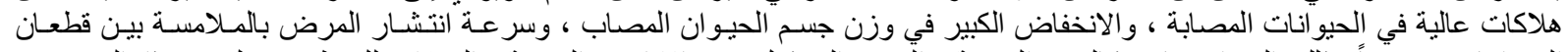

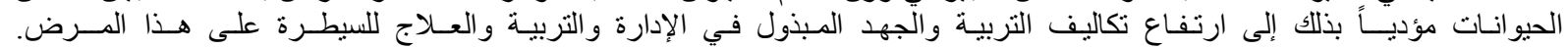
(Nicholas et al., 2008; Kilic et al., 2013)

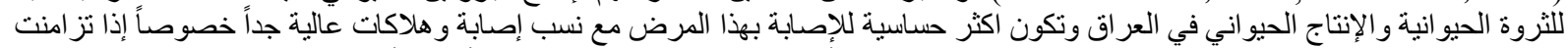

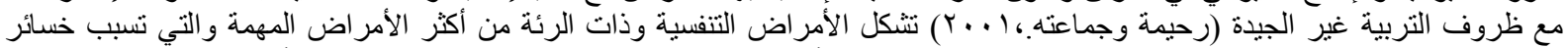

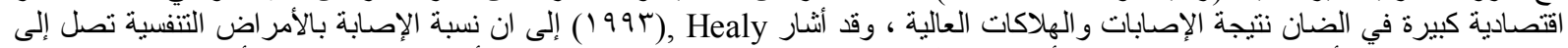

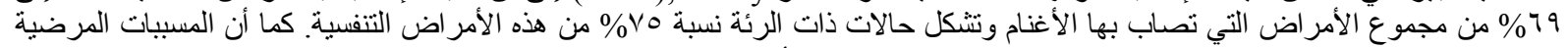

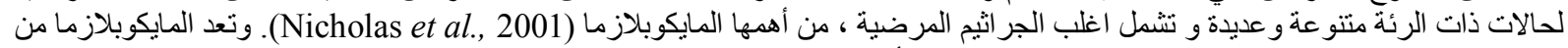

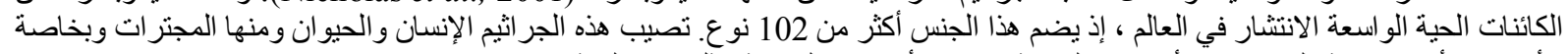

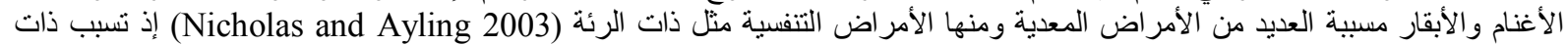

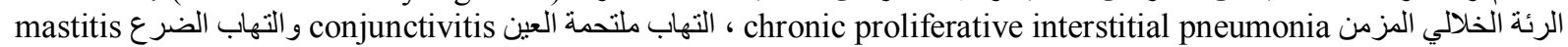




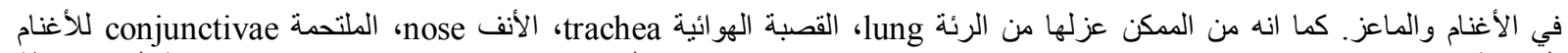

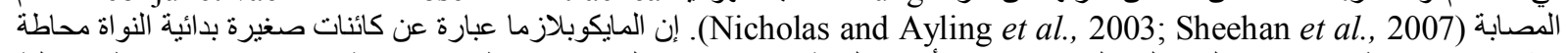

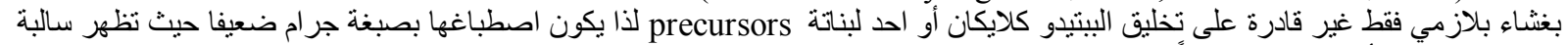

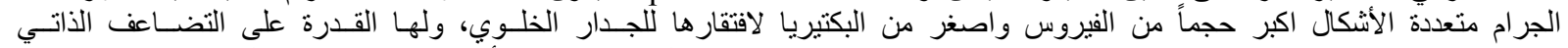
(Quinn et al., 2002). self-proliferation

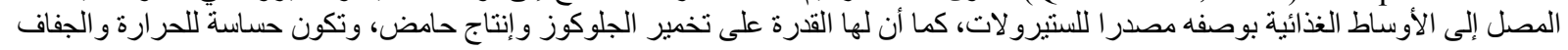

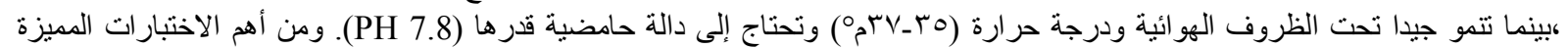

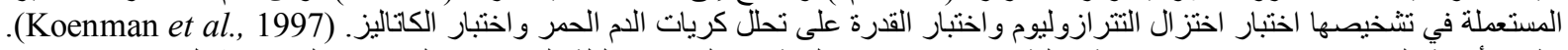

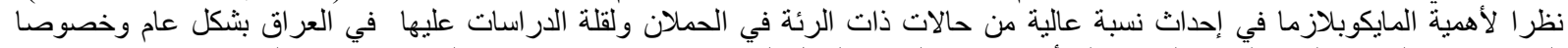

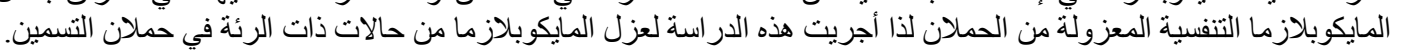

\section{MATERIALS and METHODS مـواد وطرائق العمل}

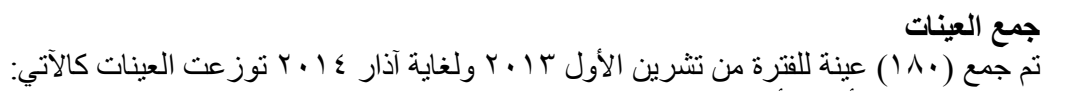

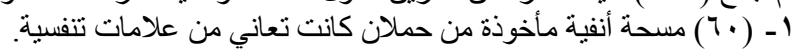

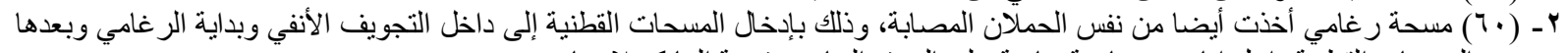

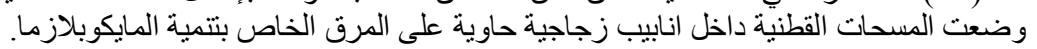

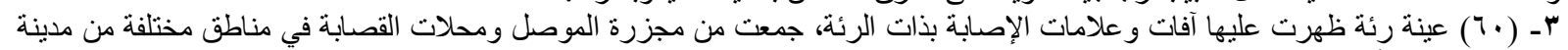

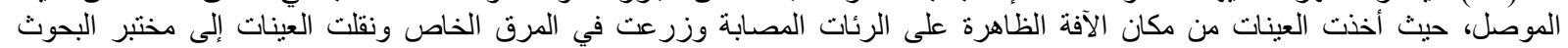
الجرثومية التابع لفرع الأحياء المجهرية في كلية الطب البيطري.

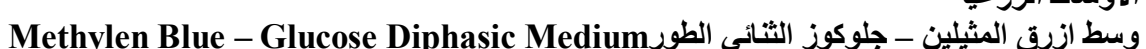

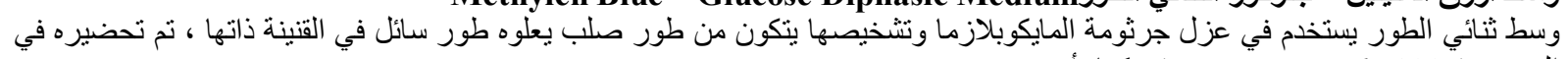
المختبر (Koneman et al., 1997) وكما يائتي:

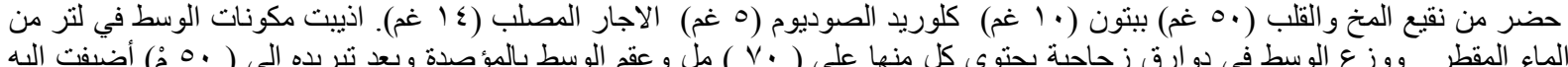
المواد الآتية:

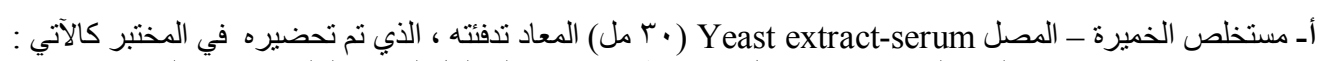

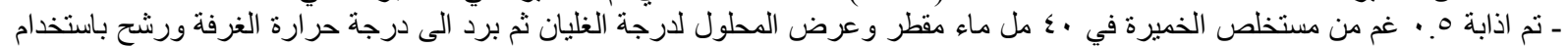

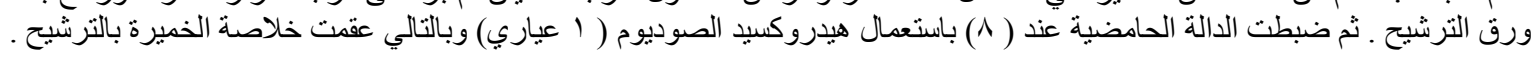

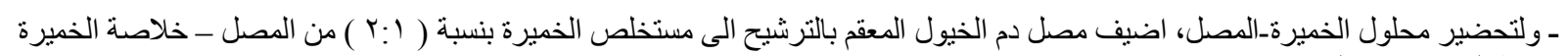
وحفظ المزيج تحت التجميد بدرجة ( •r - مُ م) .

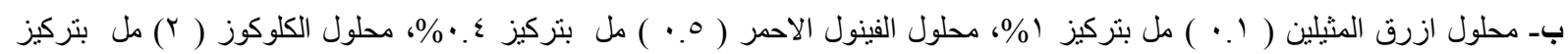

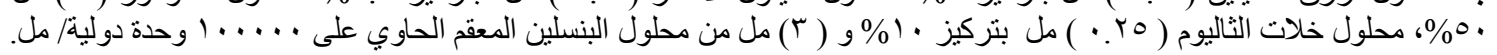

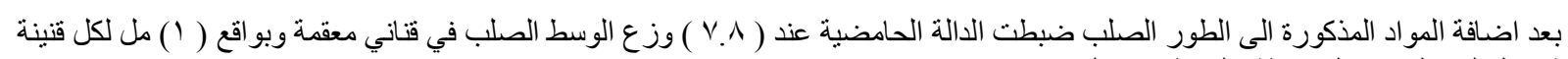
ثم ترك ليتصلب مع المحافظة على ظروف النقاد التعقيم.

Mycoplasma broth بـ الطور السيائل

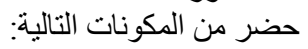

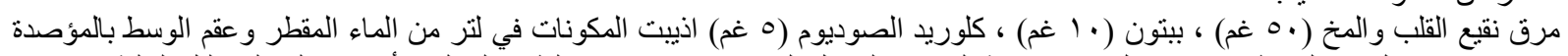

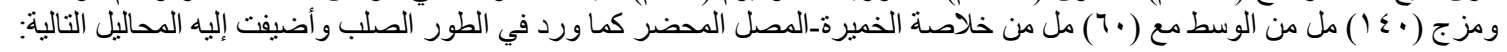

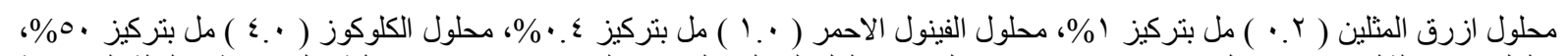

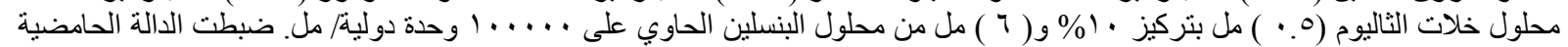

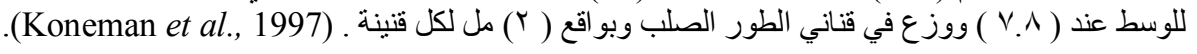

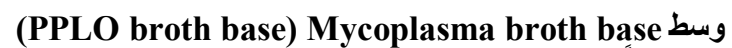

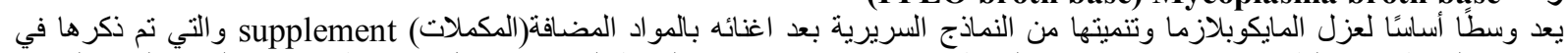

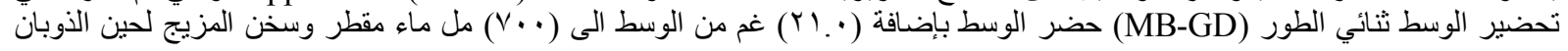




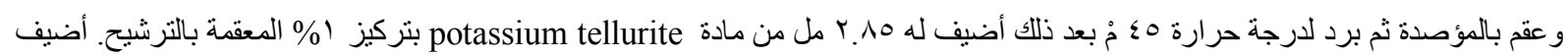

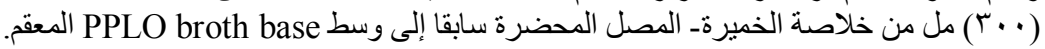

(PPLO agar base) Mycoplasma agar base وسط (V)

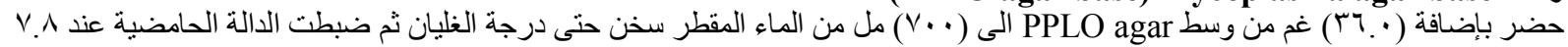
و عقم بالمؤصدة وترك ليبرد وون ثم اضيفت اليه المكملات المعقم و المحضر كما ذكر آنفاء (Koneman et al., 1997).

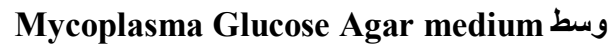

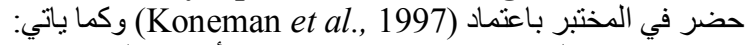

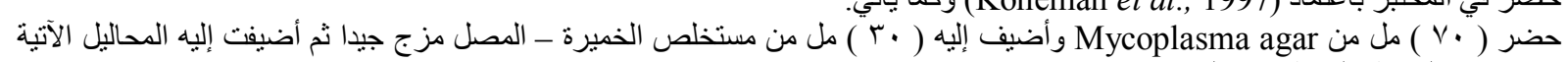
مع مر اعاة الحفاظ على ظروف التعقيم :-

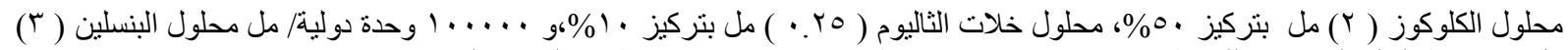

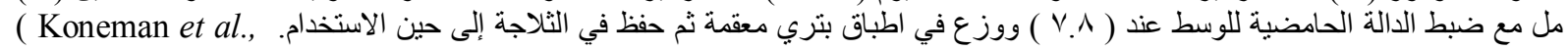

الصبغات والكواشف والمحاليل

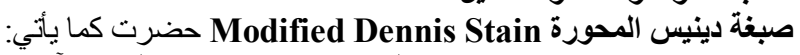

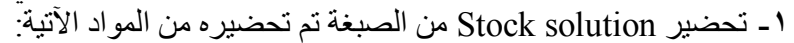

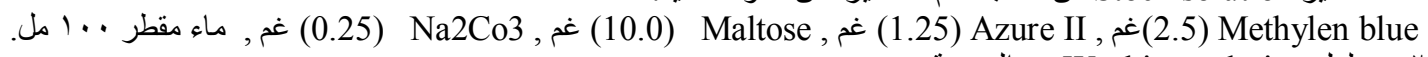

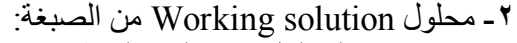
حضر بتخفيف المحلول (1) بالماء المقطر بإضافة ثلاث أحجام من الماء المقطر إلى حجم واحد من المحلول (1) (Koneman et al., 1997). المواد الاخرى

صبغة كمزا ، دارئ الفوسفات الملحي ، ازرق المثنيلين ، محلول الفينول الأحمر ، محلول الجلوكوز ، محلول خلات الثاليوم ، محلول البنسلين

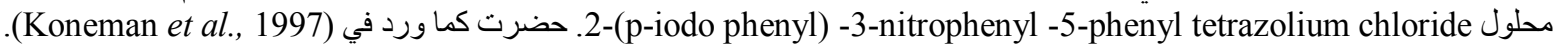

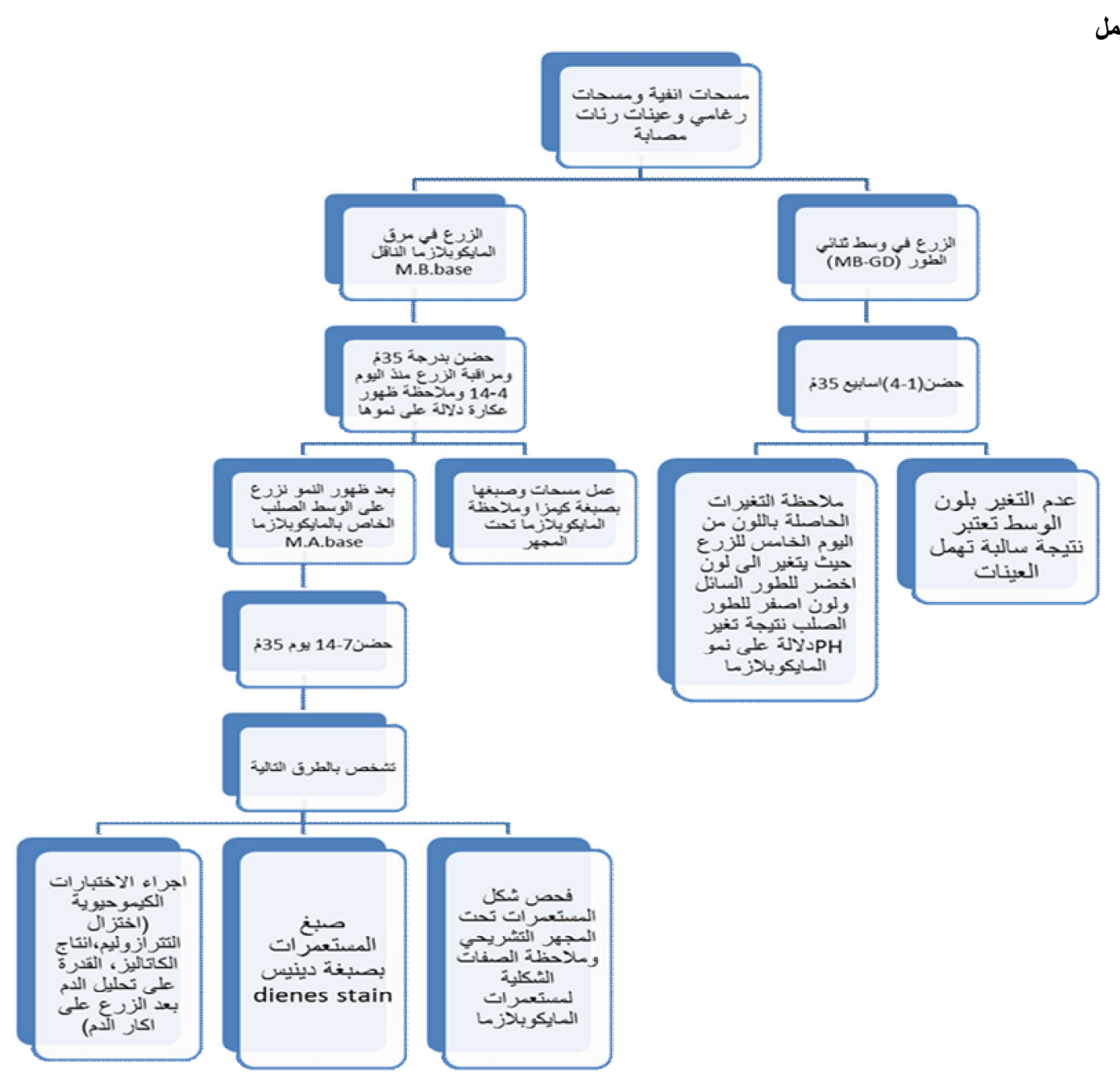


زرعت مسحات الأفف ومسحات الرغامي مباشرة في المرق الخاص بالمايكوبلازما ووضعت بالحاضنة لمدة عــ ا يوم بدرجة حرارة هب مْ مع

توفير الرطوبة اللازمة.

أخذت قطع من الرئات المصابة من مكان الآفة ووضعت مباشرة بالمرق الخاص بالمايكوبلازما وحضنت كالسابق وبعد ذلك زرعت على على وسط

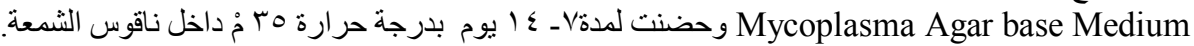
r الاختبار ات النتخيصية لجرثومة المايكوبلازما:

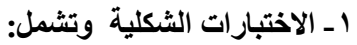

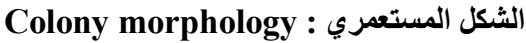

درست الصفات التُكلية وخصائص المستعمر ات من خلال نمو ها على وسط Mycoplasma Agar Medium بعد انتهاء مدة التحضين باستخدام المجهر التشريحي.

microscopic appearance : الفحص المجهري

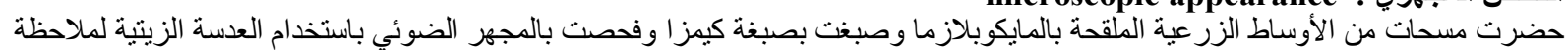

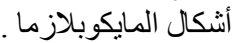

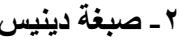

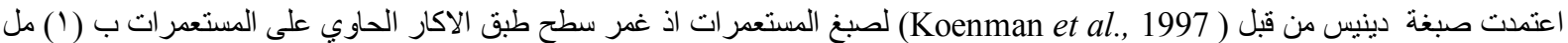

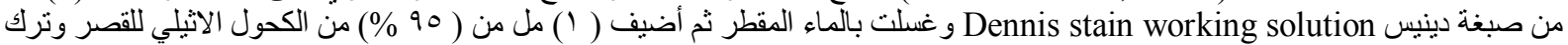

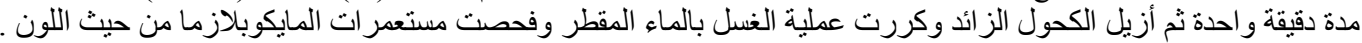

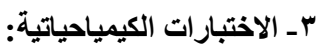

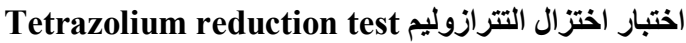

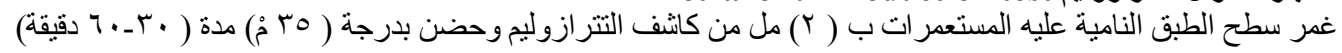

اختبار تخمر الكاربو هيدرات

استخدم الوسط أفمرار (MB-GD medium) الثنائي الطور الحاوي على الجلوكوز وازرق المثيلين والفينول الأحمر لإجراء اختبار تخمر الكاربو هيدرات.

اختبار القدرة على تحليل الام

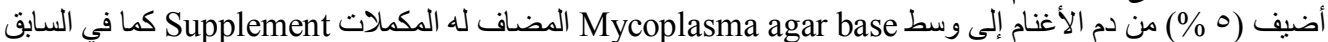
ثم وزع في أطباق بتري معقمة ولقح بالجر اثيم تحت الاختبار وحضنت الأطباق هو ائيًا بدرجة ( هـامْ) مدة ( V_O أيام) .

\section{RESULTS}

النتائــج

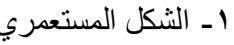

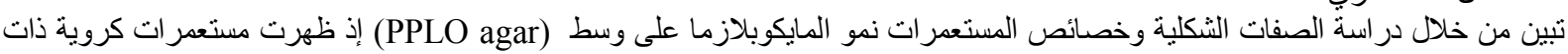

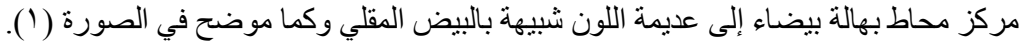

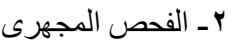

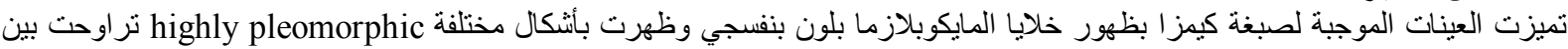

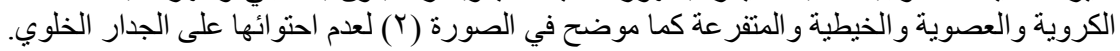

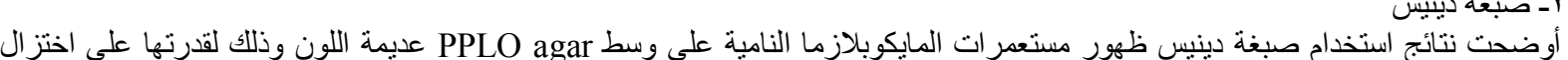

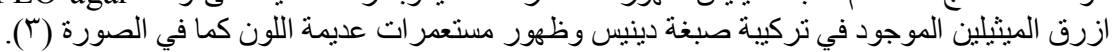

ع ـ اختبار اختز ال التترازوليم

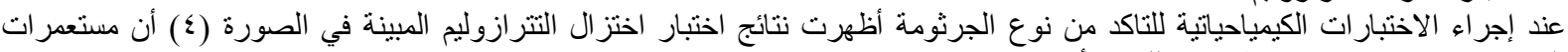

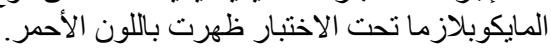

•ـ اختبار تخمر الكربو هيدرات لوحظ قدرة المايكوبلازماً على تخمير الكربو هيدرات بتحول الطور الصلب إلى اللون الأصفر والطور السائل إلى اللون الأخضر كما موضح في الصورة (0)

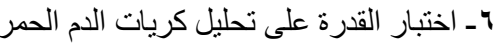

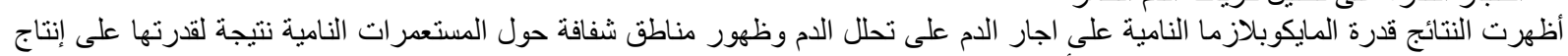

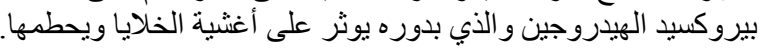

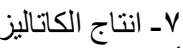
أظهرت المايكوبلازما النامية نتيجة موجبة لهذا الفحص.

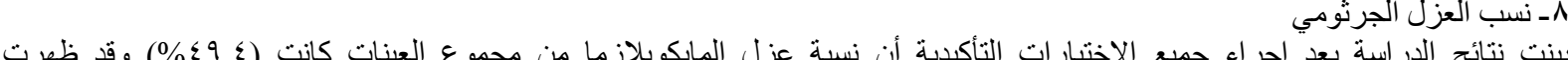

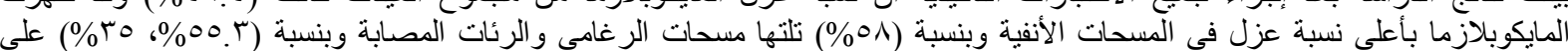
التو اللي. 

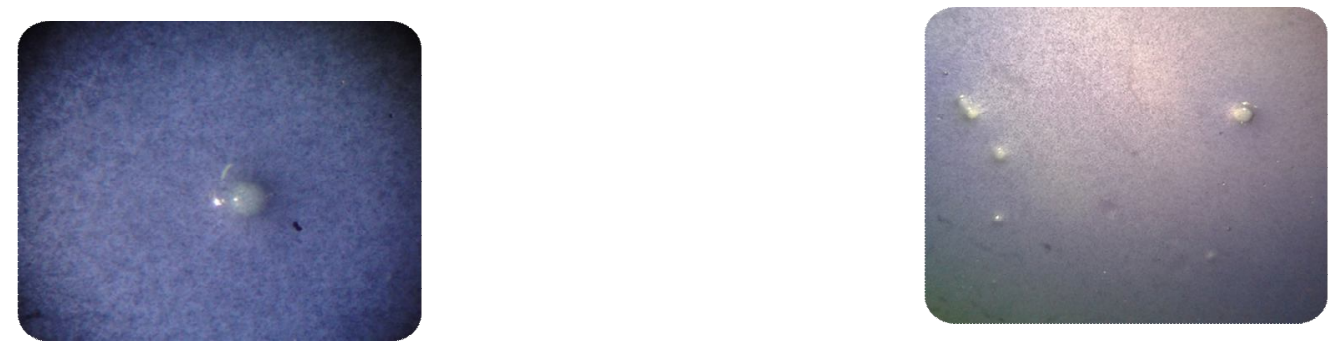

(1) الصورة (1) (لميز

المستعمر ات المجهرية ذات المظهر المميز (مظهر البيضة المقلية) تحت المجهر التشريحي

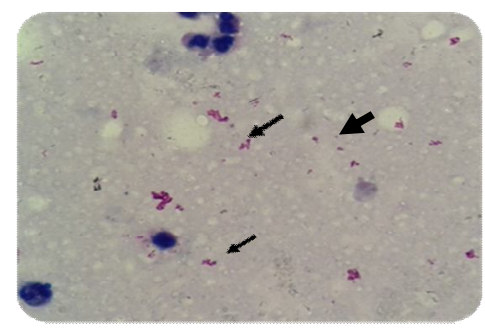

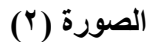

مسحة رغامي مباشرة مصبو غة بصبغة كيمز ا تتضح فيها النتيجة الموجبة لوجود المايكوبلازما وظاهرة تعدد الأشكال لخلايا المايكوبلازما.
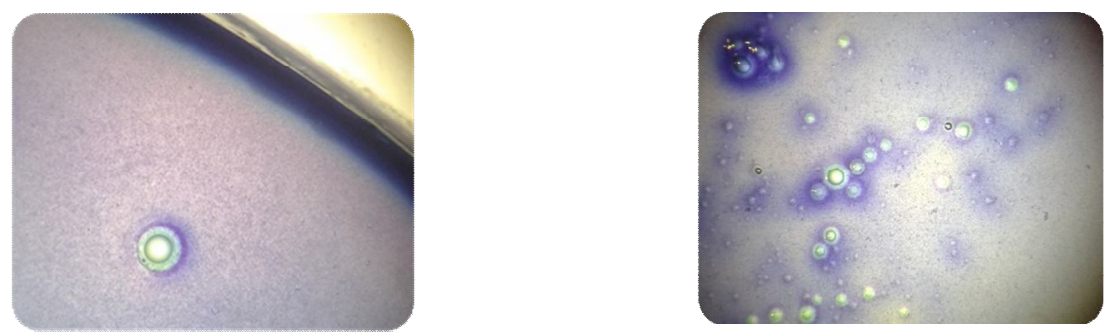

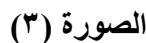

النتيجة الموجبة لاختز ال صبغة دينيس وظهور مستعمر ات عديمة اللون

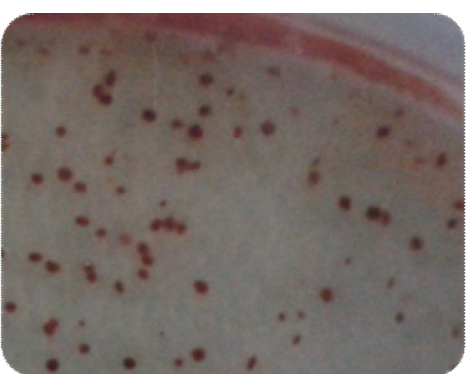

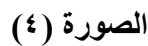

اختبار اختز ال التترازوليوم وظهور المستعمر ات باللون الأحمر

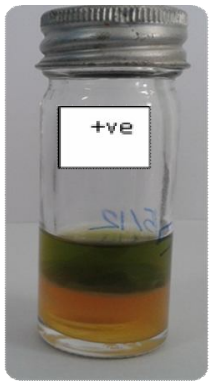

(')

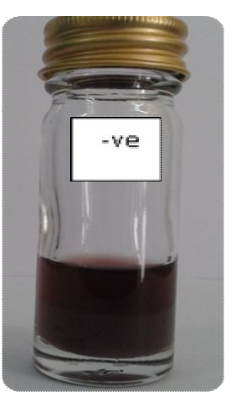

$(ب)$
الصورة (0) النمو في الوسط ثنائي الطور

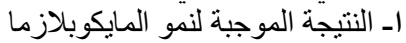
بـ النتيجة السالبة 
Assiut Vet. Med. J. Vol. 60 No. 142 July 2014

جدول 1 : أعداد و أنو اع ونسب العينات التي تم جمعها خلال فترة الدراسة.

\begin{tabular}{|c|c|c|c|}
\hline$\%$ & عدد العينات الموجبة & عدد العينات الكلي & نوع العينة \\
\hline$\Delta \wedge$ & ro & 9. & مسحات انفية \\
\hline$\Delta . r$ & r & 7. & مسحات رغامي \\
\hline ro & YI & 7. & رئـات مصابة \\
\hline$\leqslant 9 . \leqslant$ & 19 & 11. & المجموع \\
\hline
\end{tabular}

\section{DISCUSSION}

المناقشة

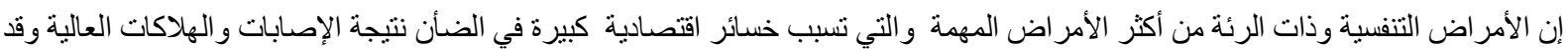

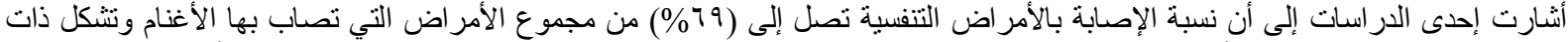

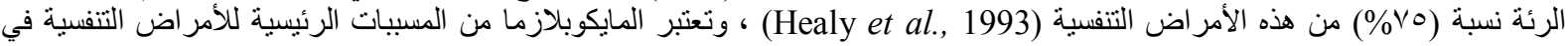

الحمان (Pitcher and Nicolas 2005).

أظهرت نتائج الدر اسة الحالية ان المستعمر ات النامية كانت نموذجية ومطابقة للمستعمر ات الخاصة بالمايكو بلازما عند تتميتها على وسط PPLO

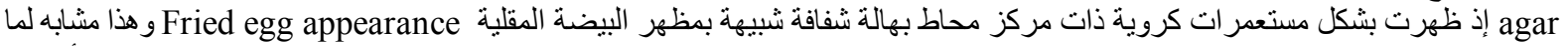
مذكور في المر اجع العلمية (Koenman et al., 1997; Quinn et al., 2002; Nester et al., 2004; Prescott et al., 2005). وأنشارت

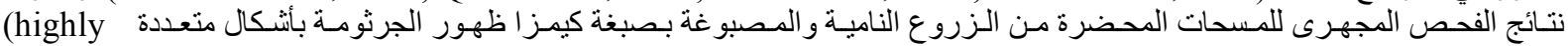
pleomorphic)

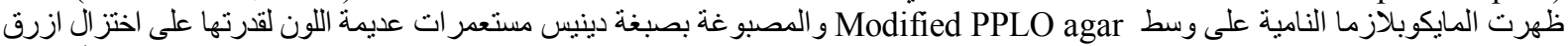

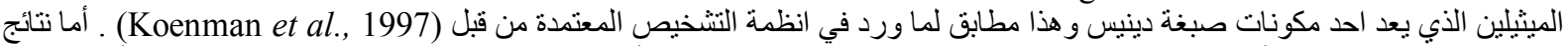

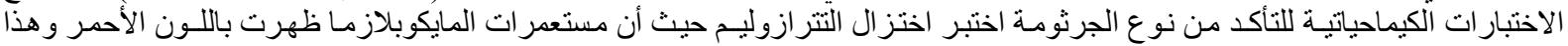

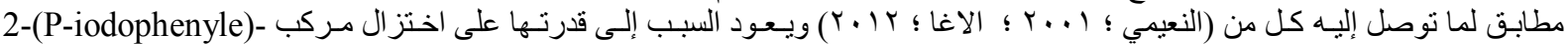

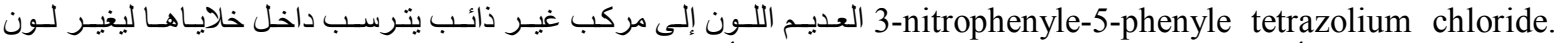

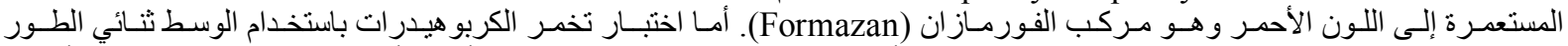

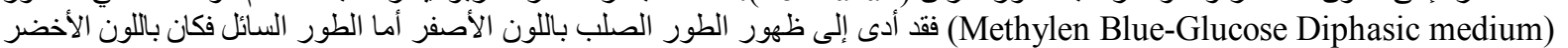

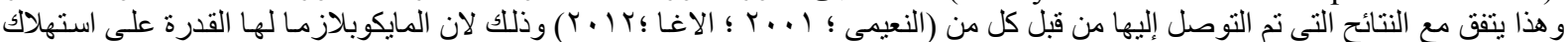

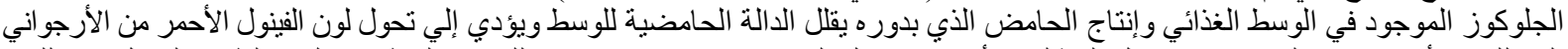

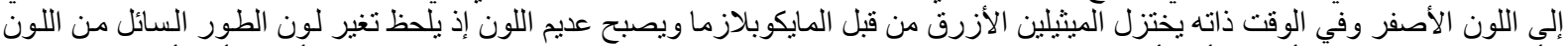

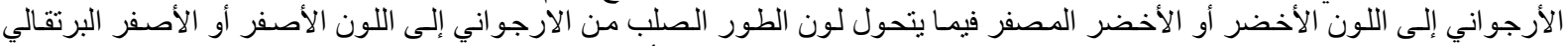

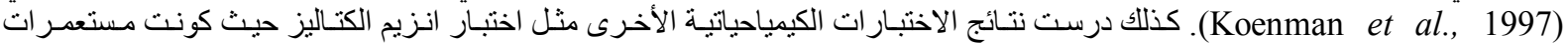

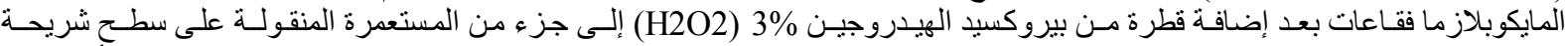

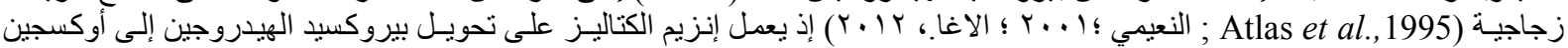

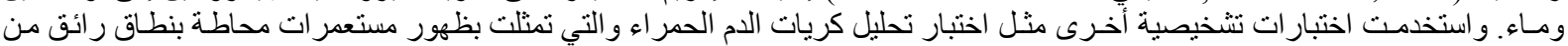

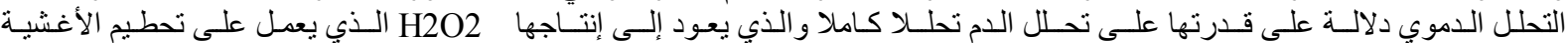

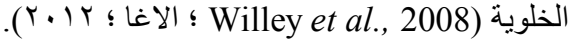

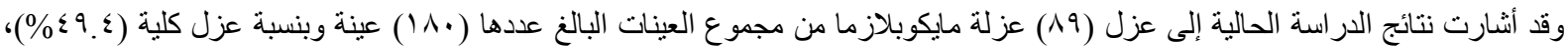

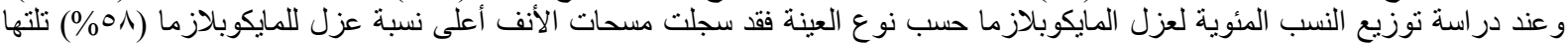

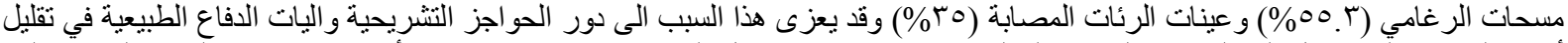

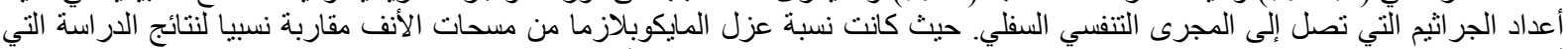

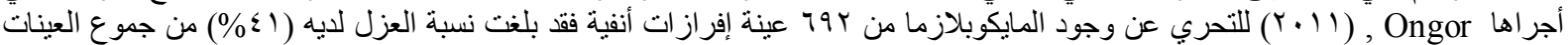

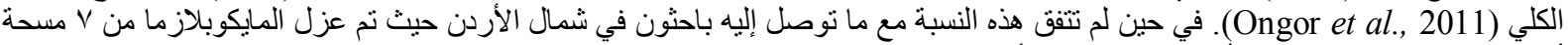

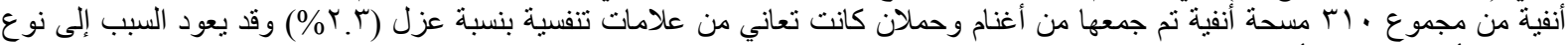

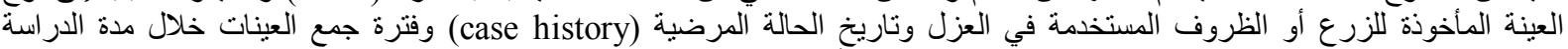
(Momani et al., 2006)

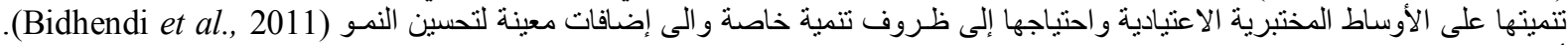

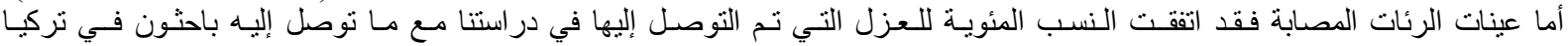
(Kilic et al., 2013)

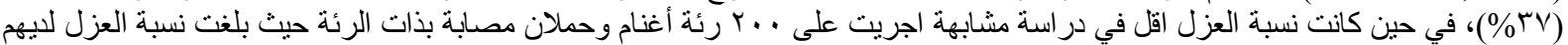

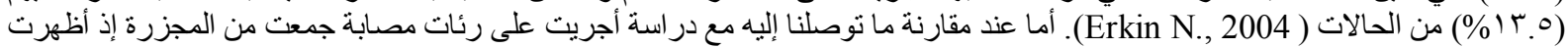

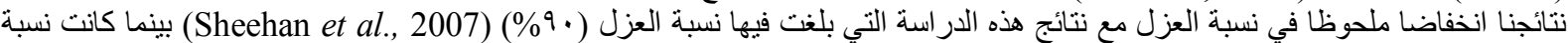

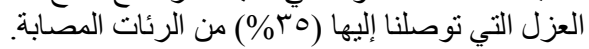




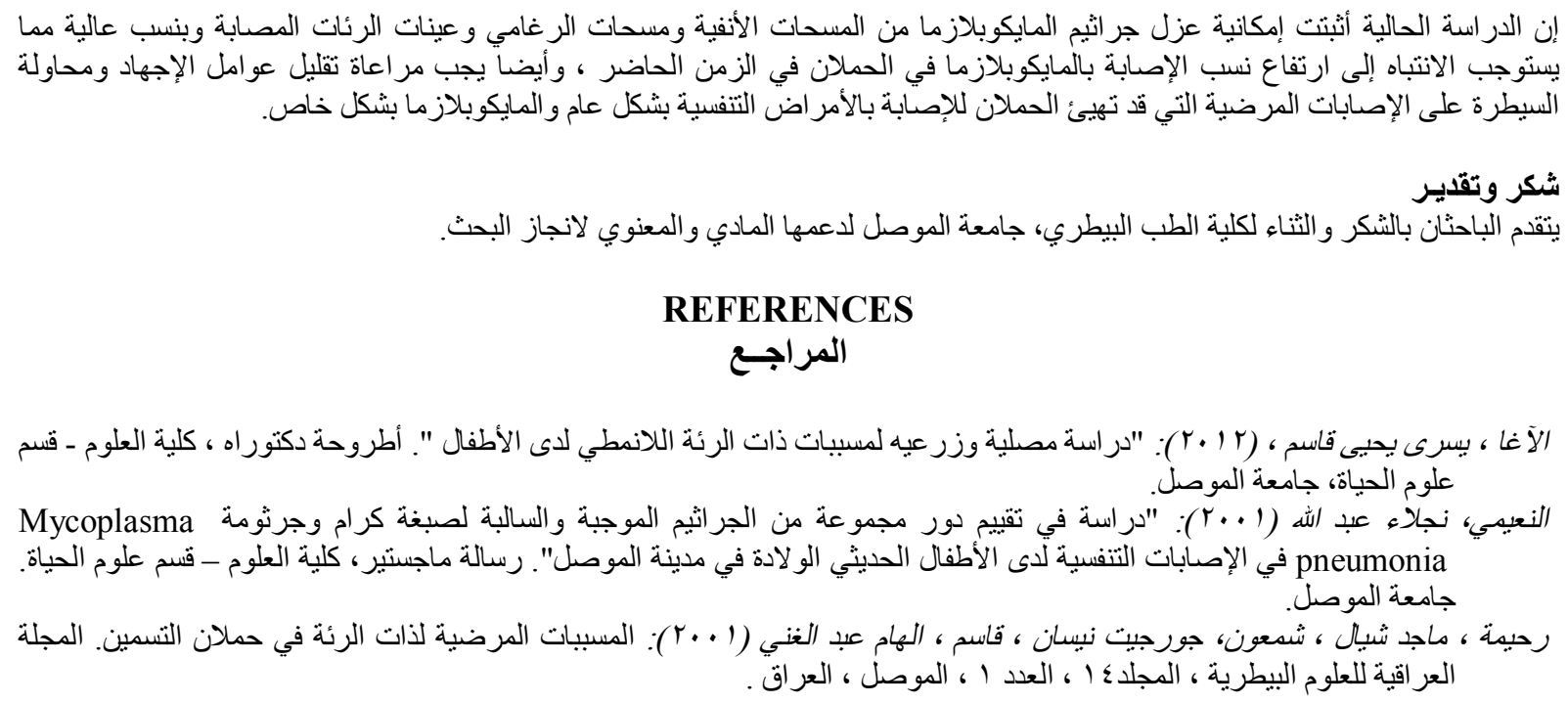

Atlas, R.M.; Brawn, A.E. and Parks, L.C. (1995): Laboratory Manual of Expermental Microbiology (2 $2^{\text {nd }}$ ed.). Mosby-Year Book, Inc. USA.

Bidhendi, M.; Khaki, S. and Langroudi, P.R. (2011): Isolation and identification of Mycoplasma agalactiae by culture and polymerase chain reaction in sheep and goat milk samples in Kordistan Province, Iran. Razi Institute, vol. 66, No. 1.

Erkin, N. (2004): The isolation and identification of Mycoplasma species in sheep and lambs that indicates pneumonia in Samsun rejoin. M.Sc. Thesis, Samsun Veterinary Control and Research Institute.

Healy, A.M.; Monaghan, M.L. and Basset, H.F. (1993): Morbidity and mortality in large irish feedlot, Microbiological and serological finding in lambs with acute respiratory disease. British. Vet. J. 149: 539-560.

Kilic, A.; Kalender, H.; Eroksuz, H.; Muz, A. and Tasdemir, B. (2013): Identification by culture, PCR, and immunohistochemistry of mycoplasmas and their molecular typing in sheep and lamb lungs with pneumonia in Estern Turkey 10: 013-0394.

Koenman, E.W.; Allen, S.D.; Janda, W.M.; Schreck enberger, P.C. and Winn, W.C. (1997): Colar atlas and text book of diagnostic Microbiology. ( $5^{\text {th }}$ ed.) Lippincot-Raven publisher, Philadelphia, USA.

Momani, A.W.; Halab, M.A.; Aboshehada, M.N.; Mieles, K.; McAuliffe, L. and Nicholas, R.A.J. (2006): Isolation and molecular identification of small ruminant Mycoplasma in Jordan, small Ruminant Research. 65: 106-112.

Nester, E.W.; Anderson, D.G.; Jr., CER.; Pearsall, Pearsall, N.M. and Nester, M.T. (2004): Microbiology.(4 ${ }^{\text {th }}$ ed.)., McGraw-Hill Companies, Inc. USA.

Nicholas, R.A.J.; Ayling, R.D. and McAuliffe, L. (2003): A Text Book of the Mycoplasma Diseases of Ruminants, CABI is a trading name of CAB International, www.cabi.org ., Pp. 132-168.

Nicholas, R.A.J.; Ayling, R.D. and Loria, G.R. (2008): Ovine Mycoplamal infections. Small Ruminant Research, 76, 92-98.

Nicholas, R.A.J.; Wood, E.; Baker, S. and Ayling, R.D. (2001): Mycoplasmas isolated from ruminants in Britain 1995-2000. In: Poveda, J.B., Fernandez, A., Frey, J., and Johansson, K.E. (eds.). Mycoplasmas of Ruminants: Pathogenicity, Diagnostics, Epidemiology and Moleculargenetics. Vol.5. European Commission, Brussels. pp. 116-120.63.

Ongor, H.; Kalin, and MN Acik, (2011): Detection of Mycoplasma ovipneumoniae from goats with nasal discharge by culture and polymerase chain reaction. Pak. Vet. J., 31(3): 244-248.

Pitcher, D. and Nicholas, R.A.J. (2005): Mycoplasma host specificity: fact or fiction? Vet. J., 170: 300-306.

Prescott, L.M. Harley, J.P. and Klein, D.A. (2005): Microbiology. Avenue of the Americas, New York. (6 ${ }^{\text {th }}$ ed.) McGraw-Hill.Companies, Inc., USA.

Quinn, P.J.; Markey, B.K.; Carter, M.E.; Donnelly, W.J. and Leonard, F.C. (2002): Mycoplasmas. In: Veterinary Microbiology and Microbial Disease. 1st ed., Black Well Publishing. Pp: 189-195.

Sheehan, M.; Casidy, J.P.; Brady, J.; Ball, H.; Doherty, M.L.; Quinn, P.J.; Nicolas, R.A.J. and Markey, B.K. (2007): An Aetiopathological Study of Chronic Bronchopneumonia in lambs in Ireland. The Veterinary Journal, 173, 630-637.

Willey, H.C.; Sherwood, L.M. and Woolverton, C.J. (2008): Microbiology. (7 $7^{\text {th }}$ ed.) McGraw Hill. USA. 